\title{
High Impedance Fault Detection using Fuzzy Logic Technique
}

\author{
Gogula vyshnavi ${ }^{1 *}$ and Avagaddi Prasad ${ }^{2}$ \\ Applied Renewable Energy Research Lab, Dept. of Electrical \& Electronic \\ Engineering, Sree Vidyanikethan Engineering College, Tirupati, AP, India \\ ${ }^{1}$ vyshnavigogula04@gmail.com, ${ }^{2}$ prasadavagaddi@gmail.com
}

\begin{abstract}
The power systems are complex and not always easy to understand. Now a days Distributed Generation (DG) based on renewable energy resources enrolled an exponential progress encouraged by the policy makers, global concerns about $\mathrm{CO}_{2}$ emissions, energy shortage, and anxiety for clean strength generation. This leads to a quick and constant upgrading of improvement in this particular region, bringing these systems at a point where their unwavering quality and fitness isn't any longer examined. The greatest challenge for electrical engineers is to provide a better protection scheme to detect the high impedance faults (HIFs). HIF conventionally happen when the primary conductor makes unwanted electrical contact with a rod surface, sod, tree limb, which restricts the flow of fault current to a level underneath that consistently detectable by conventional overcurrent devices. A novel and efficient protection scheme have to able to detect the HIFs and which can operate power system adequately, and protects the equipment as well as the public from hazardous over voltages. This paper pursues is to analysis of literature associated to HIF appearance. In this work, fuzzy logic technique used for HIF detection are assessed. The proposed HIF model gives more exact and consistent compared to other methods.
\end{abstract}

Keywords: Distribution system, High impedance faults, Fault detection techniques, Fuzzy logic technique

\section{Introduction}

Fast reliable detection of high impedance faults (HIFs) in electrical distribution systems (EDS) is a persistent challenge to electric utilities. Conventional overcurrent relays or fuses fail to detect HIFs because their fault currents are very small. The main goal of this work is to develop a novel reliable HIF detection technique for EDS. The idea of HIFs has been a subject of interest since the 1970's with the hope of determining some identifying the qualities in the waveforms for practical detection. This segment gives a short review of HIF in EDS. A HIF happens [1]- [3] when an empowered essential conductor interacts with a semi-insulated object, for example, tree, structure or gear, or touches the earth's surface, such as tar road, solid, grass, and sand. These surfaces force high impedance and point of confinement fault streams to little qualities. The mainstream of high impedance faults ensue at distribution voltages of $15 \mathrm{kV}$ and below, with the issue deteriorating at the lower voltages. The issue is less extreme at $25 \mathrm{kV}$ or more, yet HIFs can happen at these voltages also. Typically, HIF has a low current level lengthening from a couple of $\mathrm{mA}$ to $75 \mathrm{~A}$. The arcing issue has a tendency to produce high temperature to moderate humidity on most ground surfaces. The high temperature because of fault produced warmth may cause material responses that change surface conductivity. Distinctive seasons and various circumstances of day can influence ground surface conductivity. These dynamic qualities change the level and substance of HIF streams and

Received (January 13, 2018), Review Result (May 17, 2018), Accepted (May 30, 2018) 
make HIF location an irregular procedure. Two principle attributes of high impedance faults are low estimations of fault streams and the closeness of arcing marvels. The first main characteristic is due [4]- [6] to the fact that these faults have impedance high enough in the fault path which limits the fault currents to very low values this feature makes HIFs hard to be recognized by traditional over-current relays. The occurrence of arcing phenomena, the second main feature of high impedance faults, is a result of existence of air gap between conductor and a semi-insulated object or earth's surface makes a huge electrical potential distinction over a short separation because of the inclination contrast in the electric field.

Since the Impedance at the fault point is very high, the fault current nearly does not make a clear change in extent and leads to the failure of detection by conventional over current relays. At the point when high impedance fault happens, stimulated high voltage conductor may fall inside reach of work force and debilitate life security of people or human being. Also, high impedance faults are usually associated with arcing at the point of contact and they present a serious public safety hazard and a risk of arcing ignition of fires or melting of switch gear, equipment damage, etc. Therefore, from both public safety and power system operational reliability viewpoints, detection of high impedance faults is critically important. The most famous HIF detection method includes the variation of over current self-protective devices, yet this plan has driven into a few unexpected disturbances on the grounds that the electric current level coming about because of HIFs can't be separated from other non-fault cases in the power system, which influences the security of energy system. A higher reliability powers a lower security level and the other way around. In this way, the fuzzy logic technique is to [7] build up a sensitive high impedance fault identification strategy with monitoring on the power system assurance security.

\section{Fuzzy Logic Technique}

Fuzzy set concept was first introduced by Prof LoftiZadeh of the University of California in 1965. A mathematical system that examines analog input values in terms of logical variables that take on continuous values between o and 1 , in contrast to classical or digital logic, which operates on discrete values of either 1 or 0 (true or false) [8]. Fuzzy logic is widely used in machine control, the term "fuzzy" refers to the fact that the logic involved can deal with concepts [9] that cannot be expressed as the "true" or "false". Advantage of fuzzy logic has the solution to the problem can be cast in terms that human operators can understand easily. Fuzzy logic controllers are very simple, they consist input stage, processing stage, and an output stage. The input variables in a fuzzy control system are in general mapped by sets of membership functions similar to this known as fuzzy sets. The processing stage involves each appropriate rule and generates a result for each, then combines the results of the rules. The output stage converts the combined result back in to a specific control output value. The aggregated output fuzzy set serves as input to the defuzzifier. The defuzzifier combines the information in the fuzzy inputs to obtain a single crisp (non-fuzzy) output variable. To successfully design a fault detection system using [10]-[15] fuzzy logic, an understanding of the basic components of a fuzzy decision system is important. These include fuzzy logic concepts such as fuzzy sets and their properties, fuzzy rule base, and fuzzy inference system (FIS). The use of fuzzy logic enables the fault detection system to cope with uncertainties that occur during the location of fault in electrical distribution networks.

Distribution of power is one of the important aspects in power systems, when it comes to customer's satisfaction. Consumer needs continuity of power supply [16]. Power quality is the desirable trait looked by the consumer. Faults in a complex power system poses challenge to maintain power quality. Faults can only be minimized it cannot be entirely eliminated from the system. To achieve continuity in power supply, detect the 
faulty section quickly. HIFs [17] usually occur at primary network level in electric distribution systems. Detection of HIF by conventional over-current protection devices is generally difficult because they have high impedance at the fault point and do not cause an excessive change of current in the affected line. Safety is one of the important issues in distribution electricity networks. Lack of security in the power network may lead to damage to humans and equipment. The prevention is the best solution to avoid the harmful events. The HIF is one of the issues that results in death and financial damages.

\section{HIF Detection by using Fuzzy Logic Technique}

Consider the figure single diagram of IEEE-15 bus system with unbalanced load condition.

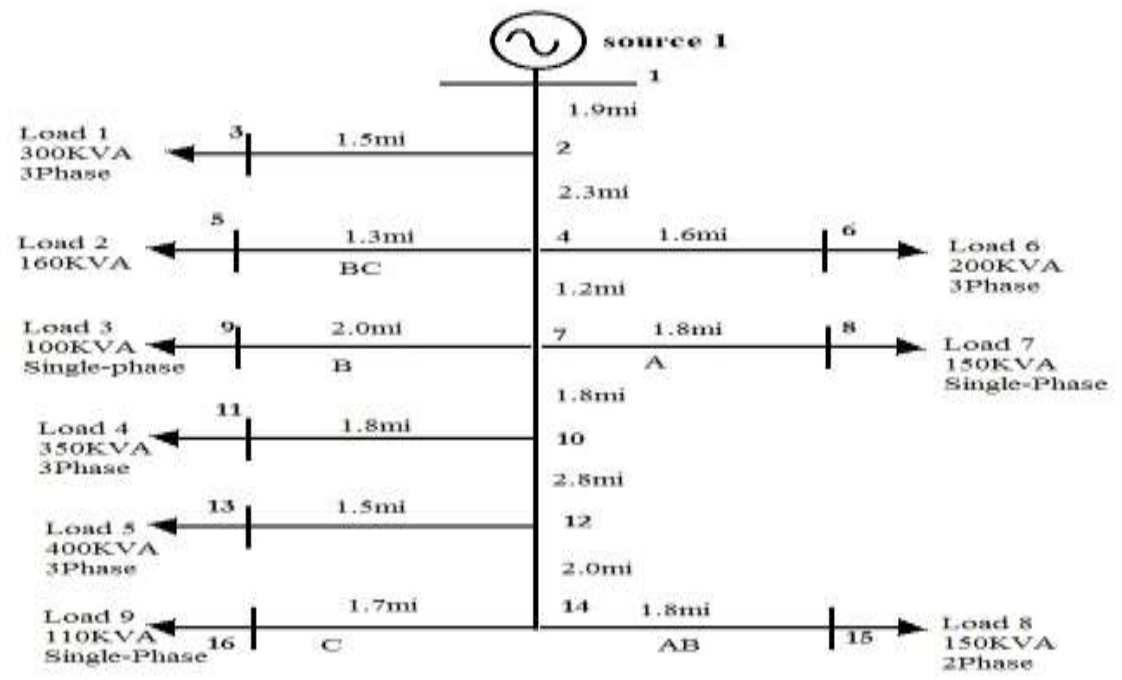

Figure 1. Single Line Diagram of IEEE-15 Bus System

The Figure 1 shows single line diagram of IEEE-15 bus system, in this diagram [18]1source, 9 loads and 15 buses are connected. Different line lengths are connected in between the buses with the help of transmission line, this single diagram implemented in MATLAB by using Simulink tools. Some of the loads are connected 3phases and some of the loads are 2 phase and single phase. It provides an interactive graphical environment and a customizable set of block libraries that let this work design, simulate, implement and test a variety of time-varying systems including power, communications, controls, signal processing, etc. The simulations for the various types of faults were carried performed and the various values for both faulted and non-faulted current were taken and recorded. These currents values taken at each phases and calculate the output value using FIS, observe all the currents values set the membership functions to inputs and output.

Calculations of fuzzy inputs by using phase a, phase $b$, and phase c currents respectively.

$$
\begin{aligned}
& u_{1}=\operatorname{sum}\left(i_{a}\right) \\
& u_{2}=\operatorname{sum}\left(i_{b}\right) \\
& u_{3}=\operatorname{sum}\left(i_{c}\right)
\end{aligned}
$$

If Eq. (1) is considered as $\mathrm{U}_{1}$, i.e., sum of the phase a, current [19] and Eq. (2) is considered as $\mathrm{U}_{2}$, i.e., sum of phase b, current [20], and Eq. (3) is considered as $\mathrm{U}_{3}$, i.e., 
sum of phase c, currents respectively, by using the above equations this work consider inputs to the FIS based on current values by setting memberships functions low (L), normal $(\mathrm{N})$, high $(\mathrm{H})$.

Consider a flowchart for HIF detection in distribution system

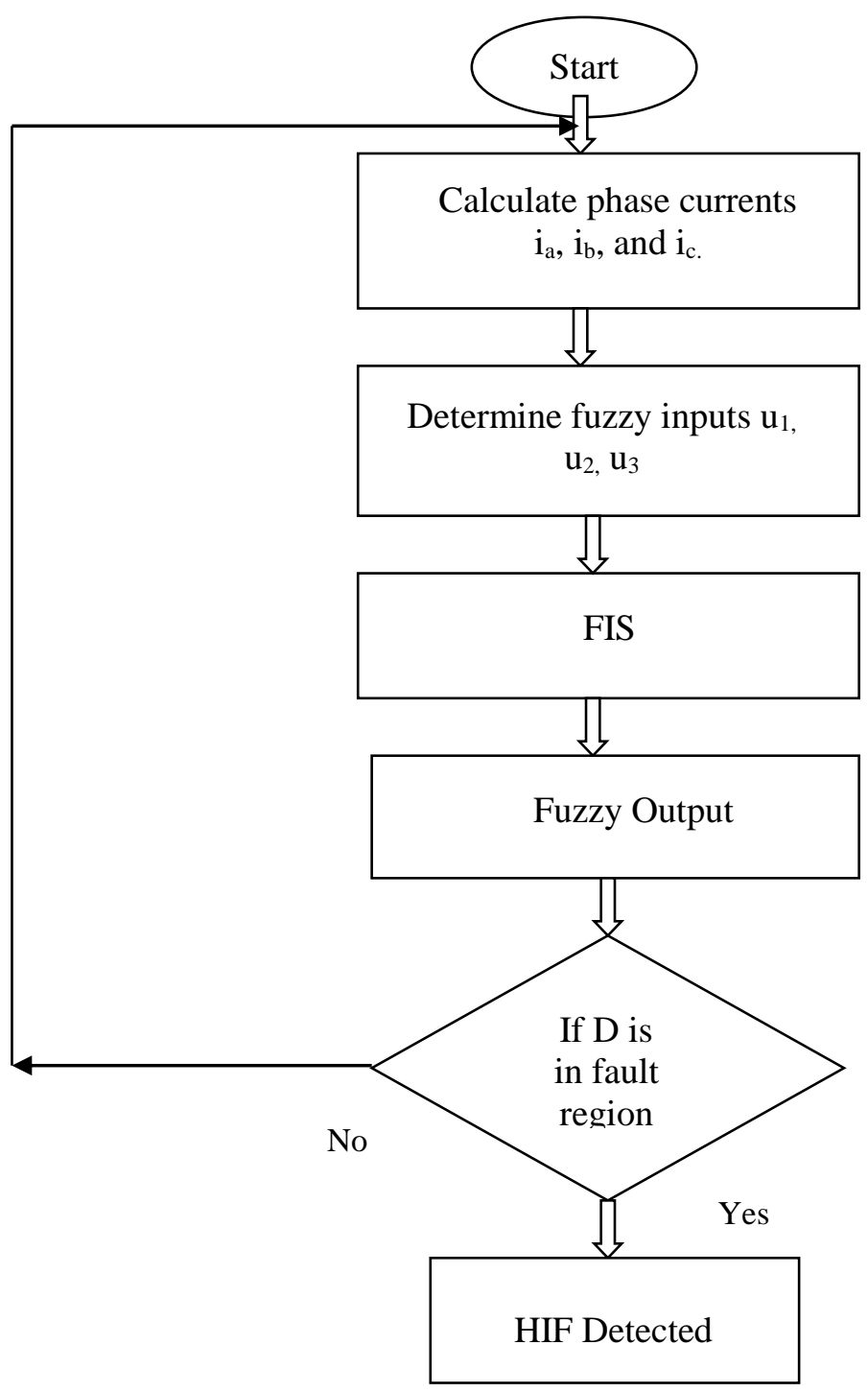

Figure 2. Flowchart of Proposed Method for HIF Detection

The Figure 2 shows flowchart of proposed method for detection of HIF in distribution system. First step to calculate phase a, phase $b$ and phase $c$ values from simulation after calculating the current values, determine the fuzzy inputs with help of phase currents these inputs $\mathrm{U}_{1}, \mathrm{U}_{2}, \mathrm{U}_{3}$, are set in to membership functions by setting the limits $\mathrm{L}, \mathrm{N}, \mathrm{H}$ rules implemented FIS by using fuzzy outputs. Aggregate all outputs of fuzzy as input to the defuzzifier. Defuzzifier shows the result is true or false.

Consider FIS for HIF detection by referring the flowchart and equations, phase current values set in to fuzzy toolbox. The Figure 3 shows develop FIS for HIF detection. In this diagram this work consider 3 inputs and 1 output i.e., $\mathrm{U}_{1}, \mathrm{U}_{2}, \mathrm{U}_{3}$ and $\mathrm{D}$ each input set into different membership functions. A fuzzy set is an extension of the conventional crisp set 


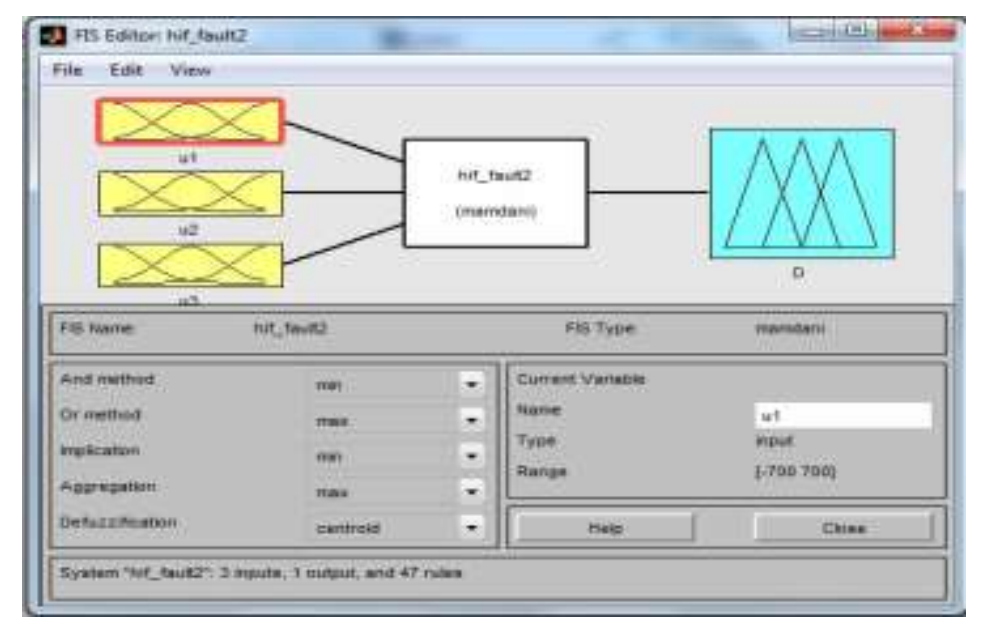

Figure 3. Developed FIS for HIF Detection

A crisp set allows only full membership or no membership of an element of a set, whereas fuzzy sets permit a gradual or smooth transition from no membership to full membership.

Consider membership functions on fuzzy input for HIF detection shown in figure.

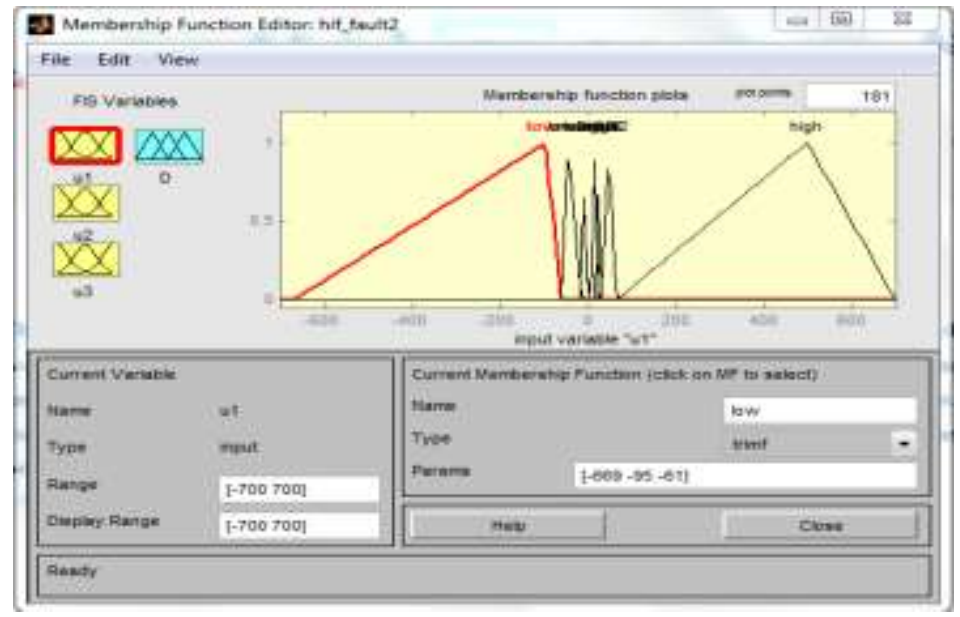

Figure 4. Membership Function for fuzzy input

The Figure 4 shows membership functions for fuzzy input for HIF detection. Membership functions set in input 1, input 2 and input 3 with the limits of low, normal, high and output set D. In this diagram considered 9 membership functions based on ranges of phase current values [18], for detection. Consider membership function on fuzzy output for HIF detection shown in figure. The Figure 5 shows membership function for fuzzy output. Aggregation is a process whereby the outputs of each rule are combined. Aggregation is performed once for each output variable. The input to the aggregation process is the truncated output fuzzy sets returned by the implication process for each rule formulated. The output of the aggregation process is the combined output fuzzy set. The aggregated output fuzzy set serves as input to the defuzzifier. The defuzzifier combines the information in the fuzzy inputs to obtain $[19,21]$ a single crisp (non-fuzzy) output variable. The simplest and most widely used center of gravity method is used for the defuzzification process. 


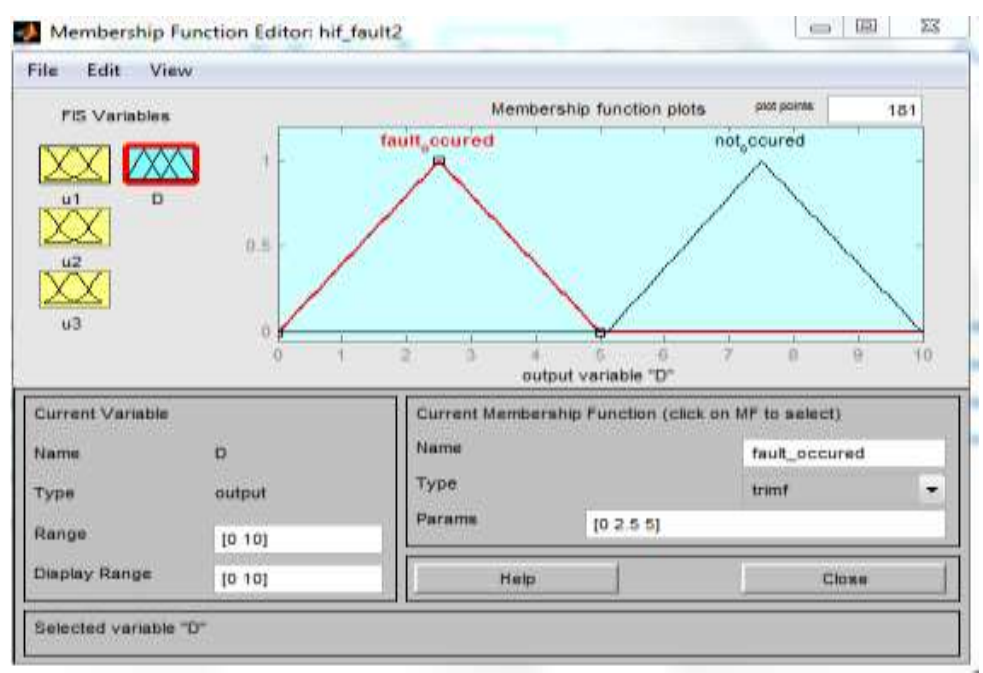

Figure 5. Membership Function for Fuzzy Output

For example, if fuzzy levels low, normal and high have membership values that are labelled $U_{1}, U_{2}$, and $U_{3}$ then the crisp output signal (D).

Consider the rules for detecting HIF in distribution systems shown in below table.

Table 1. Rules for HIF Detection

\begin{tabular}{|c|c|c|c|c|}
\hline S. No & $\operatorname{Input}_{1}\left(\mathrm{U}_{1}\right)$ & $\operatorname{Input}_{2}\left(\mathrm{U}_{2}\right)$ & $\operatorname{Input}_{3}\left(\mathrm{U}_{3}\right)$ & Output (D) \\
\hline 1. & $\mathrm{Low}_{2}$ & $\mathrm{High}_{2}$ & $\mathrm{High}_{2}$ & Fault not-occurred \\
\hline 2. & Low $_{2}$ & Normal & Normal & Fault not-occurred \\
\hline 3. & Low & Normal $_{2}$ & Normal $_{2}$ & Fault not-occurred \\
\hline 4. & Low & Normal & Normal $_{1}$ & Fault not-occurred \\
\hline 5. & $\mathrm{Low}_{2}$ & $\mathrm{High}_{2}$ & $\mathrm{High}_{3}$ & Fault not-occurred \\
\hline 6. & Low & Low & $\mathrm{Normal}_{2}$ & Fault not-occurred \\
\hline 7. & Normal $_{2}$ & High & Low & Fault not-occurred \\
\hline 8. & $\mathrm{Low}_{3}$ & High & High & Fault not-occurred \\
\hline 9. & Low $_{2}$ & High & $\mathrm{High}_{3}$ & Fault-occurred \\
\hline 10. & $\mathrm{Low}_{3}$ & $\mathrm{High}_{3}$ & $\mathrm{High}_{3}$ & Fault-occurred \\
\hline 11. & $\mathrm{Low}_{3}$ & Normal & $\mathrm{Normal}_{2}$ & Fault-occurred \\
\hline 12. & $\mathrm{Low}_{3}$ & Normal & $\mathrm{Normal}_{2}$ & Fault-occurred \\
\hline 13. & $\mathrm{Low}_{2}$ & High & $\mathrm{High}_{2}$ & Fault-occurred \\
\hline 14. & $\mathrm{Low}_{3}$ & $\mathrm{Low}_{3}$ & $\mathrm{Low}_{3}$ & Fault-occurred \\
\hline 15. & $\mathrm{Normal}_{3}$ & $\mathrm{High}_{3}$ & $\mathrm{High}_{3}$ & Fault-occurred \\
\hline 16. & $\mathrm{Low}_{2}$ & $\mathrm{High}_{2}$ & $\mathrm{High}_{2}$ & Fault-occurred \\
\hline 17. & Low $_{2}$ & $\mathrm{High}_{3}$ & $\mathrm{High}_{3}$ & Fault-occurred \\
\hline 18. & Low & High & $\mathrm{High}_{3}$ & Fault-occurred \\
\hline 19. & $\mathrm{Low}_{3}$ & $\mathrm{Normal}_{2}$ & $\mathrm{Low}_{3}$ & Fault-occurred \\
\hline 20. & $\mathrm{Normal}_{3}$ & $\mathrm{Low}_{3}$ & Normal & Fault-occurred \\
\hline
\end{tabular}

Table 1 shows rules for fault detection same rules are implemented in FIS. If input $_{1}$ is low $_{2}$ and input 2 is high and input is $_{3}$ high $_{3}$ then output (D) will shows the fault not occurrence and fault occurrence. The above rules are implemented in FIS we get output in terms of true or false. Different levels of the fault currents and voltages for different fault conditions on the distribution lines are classified into [20, 22] various degrees of membership functions- Low, Normal, and High. 
Practically implement the rules in FIS, it shows whether the fault is occurred or not.

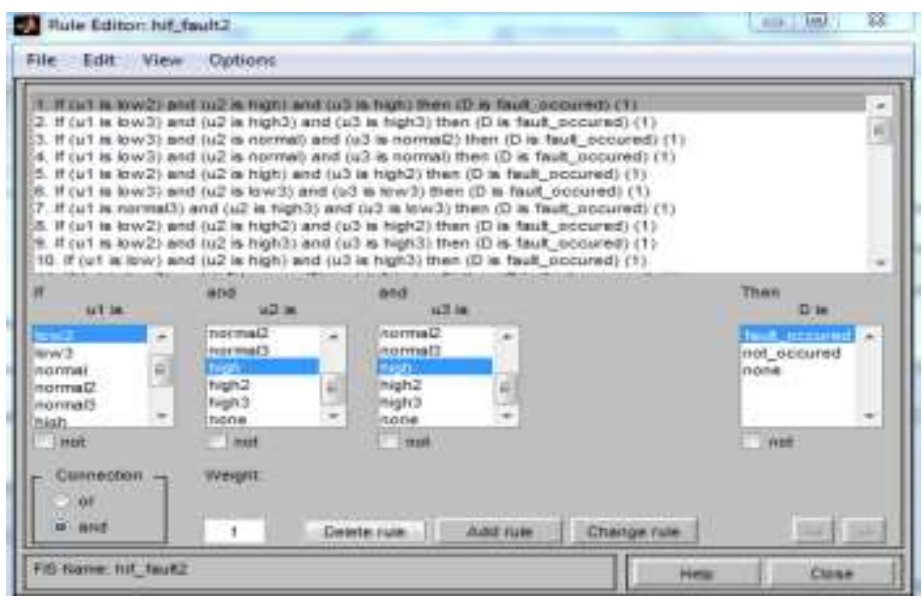

Figure 6. Rules Implemented Practically in FIS for HIF Detection

The Figure 6 shows rules implemented in FIS, membership functions set limits between $\mathrm{L}, \mathrm{N}, \mathrm{H}$. If input 1 is $\mathrm{U}_{1}$, input 2 is $\mathrm{U}_{2}$, and input 3 is $\mathrm{U}_{3}$. These are the rules implemented in FIS practically. This work validate the accuracy and performance of the fuzzy logic based fault diagnostic system as described in this work based on the $[23,24]$ test radial distribution system on which the fault simulation was performed.

\section{Results and Discussions}

By using the above equations, rules and FIS, results can be obtained it shown in below table.

Table 2. Results Obtained from FIS for HIF Detection

\begin{tabular}{|c|c|c|c|c|c|c|}
\hline S. No & $\begin{array}{c}\text { Fault } \\
\text { applied in } \\
\text { between } \\
\text { buses }\end{array}$ & $\begin{array}{c}\text { Input }_{1} \\
\left(\mathrm{U}_{1}\right)\end{array}$ & $\begin{array}{c}\text { Input }_{2} \\
\left(\mathrm{U}_{2}\right)\end{array}$ & $\begin{array}{c}\text { Input }_{3} \\
\left(\mathrm{U}_{3}\right)\end{array}$ & $\begin{array}{c}\text { Fuzzy } \\
\text { output } \\
(\mathrm{D})\end{array}$ & $\begin{array}{c}\text { Fault } \\
\text { detected } \\
\text { or not }\end{array}$ \\
\hline 1. & $\begin{array}{c}\mathrm{b}_{12} \\
\text { (without fault) }\end{array}$ & -91.6734 & 49.9889 & 43.3937 & 7.5338 & No \\
\hline 2. & $\begin{array}{c}\mathrm{b}_{12} \\
\text { (with HIF fault) }\end{array}$ & -54.2043 & 110.7868 & 89.2704 & 2.5 & Yes \\
\hline 3. & $\mathrm{~b}_{23}$ & -25.6526 & 127.3980 & 121.4925 & 2.5 & Yes \\
\hline 4. & $\mathrm{~b}_{34}$ & -6.1363 & 25.0098 & 24.3786 & 2.5 & Yes \\
\hline 5. & $\mathrm{~b}_{45}$ & -31.4151 & 94.3506 & 87.9906 & 5 & Yes \\
\hline 6. & $\mathrm{~b}_{56}$ & -0.000024 & 6.1294 & 5.8647 & 2.5 & Yes \\
\hline 7. & $\mathrm{~b}_{67}$ & -6.2008 & 15.1515 & 14.4666 & 2.5 & Yes \\
\hline 8. & $\mathrm{~b}_{78}$ & -31.0093 & 68.7731 & 62.7722 & 5 & Yes \\
\hline 9. & $\mathrm{~b}_{89}$ & -5.3994 & -0.0000146 & -0.00002 & 5 & Yes \\
\hline 10. & $\mathrm{~b}_{9-10}$ & 0.000274 & 23.5040 & -0.000173 & 2.5 & Yes \\
\hline 11. & $\mathrm{~b}_{10-11}$ & -31.4152 & 23.9266 & 22.2198 & 2.5 & Yes \\
\hline 12. & $\mathrm{~b}_{11-12}$ & -14.5395 & 23.9266 & 22.2198 & 2.5 & Yes \\
\hline 13. & $\mathrm{~b}_{12-13}$ & -21.8907 & 30.4884 & 31.4371 & 2.5 & Yes \\
\hline 14 & $\mathrm{~b}_{13-14}$ & -19.0376 & 25.6939 & 23.4561 & 5 & Yes \\
\hline 15 & $\mathrm{~b}_{14-15}$ & -687.4206 & 663.4115 & 21.3609 & 5 & Yes \\
\hline 16. & $\mathrm{~b}_{15-16}$ & -4.2413 & 4.2413 & -0.000026 & 5 & Yes \\
\hline 17. & $\mathrm{~b}_{16}$ & 0.0000162 & -0.0000251 & 6.1229 & 5 & Yes \\
\hline
\end{tabular}


The Table 2 demonstrates the outcomes got from the recreation that qualities actualized in FIS, in the wake of executing the guidelines yield got fault recognized or not based HIF and Non-HIF, whether compare to all phase current values in $9^{\text {th }}$ bus have less current values.

\section{Conclusion}

This work performs an extensive overview of the exposition of HIF, with the emphasis on its detection technique, and including HIF modelling. Additionally, a comprehensive set of criteria is utilized to compare the HIF fault from non-HIF states. At long last, a conceivable way to the future of the HIF field is proposed. A HIF detection approach in fuzzy logic has been proposed in this work, the work has been done on IEEE-15 bus test system utilizing MATLAB/SIMULINK. This work has been shown to be capable of distinguishing the majority of normal operation from abnormal events.

\section{References}

[1] Z. Liang, "High impedance fault detection in power distribution systems with impedance-based methods in frequency domain", (Doctoral dissertation, University of British Columbia), (2016).

[2] A. E. Emanuel, D. Cyganski, J. A. Orr, S. Shiller and E. M. Gulachenski, "High impedance fault arcing on sandy soil in $15 \mathrm{kV}$ distribution feeders: contributions to the evaluation of the low frequency spectrum", IEEE Transactions on Power Delivery, vol. 5, no. 2, (1990), pp. 676-686.

[3] S. H. Mortazavi, Z. Moravej and S. M. Shahrtash, "A hybrid method for arcing faults detection in large Distribution networks", International Journal of Electrical Power \& Energy Systems, Elsevier, vol. 94, no. $16,(\mathbf{2 0 1 8})$, pp. 141-150.

[4] A. Bahmanyar and S. Jamali, "Fault location in active distribution networks using non-Synchronized measurements", International Journal of Electrical Power \& Energy Systems, Elsevier, vol. 93, no. 45, (2017), pp. 451-458.

[5] W. C. Santos, "High impedance fault detection by using wavelet and fuzzy inference system", International Conference on Power Systems Transients Vancouver, Canadá, (2013) July 18-20.

[6] M. R. Haghifam, A. R. Sedighi and O. P. Malik, "Development of a fuzzy inference system based on genetic algorithm for high impedance fault detection", IEEE Transactions on Smart Grid, vol. 6, no. 2, (2015), pp. 894-902.

[7] B. Das and J. V. Reddy, "Fuzzy-logic-based fault classification scheme for digital distance protection", IEEE Trans Power Delivery, vol. 20, (2005), pp. 609-16.

[8] B. Das, "Fuzzy logic-based fault-type identification in unbalanced radial power distribution system", IEEE Trans Power Delivery, vol. 21, (2006), pp. 278-85.

[9] F. G. Jota and P. R. S. Jota, "High-impedance fault identification using a fuzzy reasoning system", IEE Proceedings-Generation, Transmission and Distribution, (1998), pp. 656-662.

[10] S. S. Gururajapathy, H. Mokhlis and H. A. Illias, "Fault location and detection techniques in power distribution systems with distributed generation", A review. Renewable and Sustainable Energy Reviews, (2017), pp. 949-958.

[11] N. Bahador, H. R. Matinfar and F. Namdari, "Proposition of inter harmonic-based methodology for high-impedance fault detection in distribution systems", IET Generation, Transmission \& Distribution, vol. 9, no. 16, (2015), pp. 2593-2601.

[12] F. Ruz and J. A. Fuentes, "Fuzzy decision making applied to high impedance fault detection in compensated neutral grounded MV distribution systems", In Developments in Power System Protection, 2001, Seventh International Conference on IEEE, IET, (2001), pp. 307-310.

[13] N. Kumar, M. Sharma, A. Sinha and I. Bhushan, "Fault Detection on Radial Power Distribution System using fuzzy logic", (2015).

[14] S. S. Gururajapathy, H. Mokhlis and H. A. Illias, "Fault location and detection techniques in power distribution systems with distributed generation", A review. Renewable and Sustainable Energy Reviews, vol. 74, (2017), pp. 949-958.

[15] W. Zhang, Y. Jing and X. Xiao, "Model-Based General Arcing Fault Detection in Medium-Voltage Distribution Lines", IEEE Transactions on Power Delivery, vol. 10, no. 4, (2015) September, pp. 22312241.

[16] Y. Li, S. Zhang, H. Li, Y. Zhai, W. Zhang and Y. Nie, "A fault location method based on genetic algorithm for high-voltage direct current transmission line", Eur Trans Electr Power, vol. 22, (2012), pp. 866-78.

[17] A. K. Pradhan, A. Routray and B. Biswal, "Higher order statistics-fuzzy integrated scheme for fault classification of a series-compensated transmission line", IEEE Trans Power Delivery, (2004), pp. 8913. 
[18] Z. Liang, "High impedance fault detection in power distribution systems with impedance Based methods in frequency domain", Ph.D. Thesis, Sun Yat-sen University, (2016) October.

[19] R. Orlowski, "Fault detection and location on $22 \mathrm{kv}$ and $11 \mathrm{kv}$ distribution feeders", Ph.D. Thesis, Victoria University of Technology, Footscray Park Campus, (2006) June.

[20] Yadav AS aA, "Fuzzy inference system approach for locating series, shunt, and simultaneous seriesshunt faults in double circuit transmission lines", Comput Intell Neurosci., (2015).

[21] S. Adhikari, N. Sinha and T. Dorendrajit, "Fuzzy logic based on-line fault detection and classification in transmission line", Springer plus, vol. 5, (2016).

[22] F. G. Jota and P. R. S. Jota, "High impedance fault identification using fuzzy reasoning system", IEEE Workshop on Environmental, Energy, and Structural Monitoring Systems (EESMS), (2006), pp. 1-6.

[23] P. Minfang, H. Yigang, T. Yi, H. Hongli and S. Xueyi, "Line Fault Location in a Distribution Network Based on K-fault Diagnosis Method", Proceedings of the 2003 IEEE International Conference on Robotics, Intelligent systems and signal processing, Changsha, China, vol. 20, no. 4, (2003), pp. 220305.

[24] H. F. Zhang, Z. C. Pan and Z. Z. Sang, "Fault locating in ungrounded and compensated systems", Proceedings of the Eighth IEEE International Conference on Developments in Power System Protection, vol. 2, no. 1, (2004), pp. 469-472.

\section{Authors}

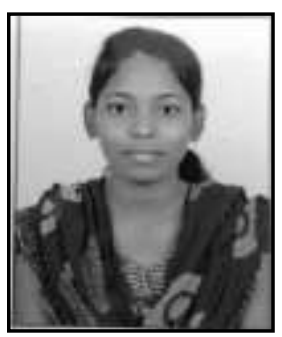

Gogula Vyshnavi was born in Andhra Pradesh, India, on January 24, 1994. She received her B. Tech degree in Electrical and Electronics Engineering from JNTU Anantapuramu in 2015. At present, she is pursuing M. Tech in Electrical Power System at the Department of Electrical and Electronic Engineering in Sree Vidyanikethan Engineering College, Andhra Pradesh, India. Her main research interest is power system protection, distributed generation, specifically detection and location faults in distribution system.

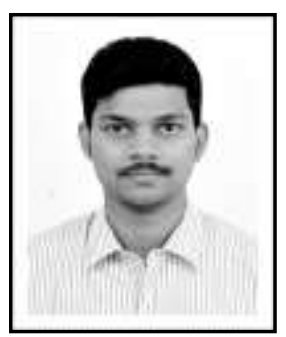

Avagaddi Prasad was born in India in 1989. He received his B. Tech degree in Electrical and Electronics Engineering from JNTU Kakinada, Andhra Pradesh, India in 2011. M.Tech degree in Power Systems and Automation from GITAM University, Andhra Pradesh, India in 2013 and $\mathrm{PhD}$ degree in School of Electrical Engineering from VIT University, Tamil Nadu, India in 2017. He worked as an Assistant Professor in department of Electrical and Electronics Engineering, VITS College of Engineering, Andhra Pradesh, India from June, 2013 to June, 2014. He is currently working as Associate Professor in department of Electrical and Electronics Engineering, Sree Vidyanikethan Engineering College, Andhra Pradesh, India. His major scientific interest is focused on power system protection, fault analysis, power quality, and soft computing techniques. 
International Journal of Grid and Distributed Computing

Vol. 11, No. 9 (2018) 